\title{
Viruses and neuroinflammation in multiple sclerosis
}

\author{
Rosella Mechelli, ${ }^{1,2}$, Carmela Romano ${ }^{3}$, Roberta Reniè ${ }^{3}$, Grazia Manfrè ${ }^{1}$, Maria Chiara Buscarinu ${ }^{3}$, Silvia \\ Romano $^{3}$, Antonio Marrone ${ }^{3}$, Rachele Bigi ${ }^{3}$, Gianmarco Bellucci ${ }^{3}$, Chiara Ballerini ${ }^{3}$, Benedetta Angeloni ${ }^{3}$, \\ Virginia Rinaldi ${ }^{3}$, Marco Salvetti ${ }^{3,4}$, Giovanni Ristori ${ }^{3,5}$ \\ 'Department of Human science and promotion of quality of life, San Raffaele Roma Open University, Rome 00166, Italy. \\ ${ }^{2}$ IRCCS San Raffaele Pisana, Rome 00166, Italy. \\ ${ }^{3}$ Centre for Experimental Neurological Therapies (CENTERS), Department of Neurosciences, Mental Health and Sensory Organs, \\ Sapienza University of Rome, Rome 00189, Italy. \\ ${ }^{4}$ IRCCS Istituto Neurologico Mediterraneo (INM) Neuromed, Pozzilli 86077, Italy. \\ ${ }^{5}$ Neuroimmunology Unit, IRCCS Fondazione Santa Lucia, Rome, 00179, Italy.
}

Correspondence to: Dr. Rosella Mechelli, Department of Human science and promotion of quality of life, San Raffaele Roma Open University, Via di Val Cannuta, 247, Rome 00166, Italy. E-mail: rosella.mechelli@uniroma5.it; Dr. Marco Salvetti, Centre for Experimental Neurological Therapies (CENTERS), Department of Neurosciences, Mental Health and Sensory Organs, Sapienza University of Rome, Via di Grottarossa, 1035-1039, Rome 00189, Italy. E-mail: marco.salvetti@uniroma1.it

How to cite this article: Mechelli R, Romano C, Reniè R, Manfrè G, Buscarinu MC, Romano S, Marrone A, Bigi R, Bellucci G, Ballerini C, Angeloni B, Rinaldi V, Salvetti M, Ristori G. Viruses and neuroinflammation in multiple sclerosis. Neuroimmunol Neuroinflammation 2021;8:269-83. https://dx.doi.org/10.20517/2347-8659.2021.01

Received: 3 Jan 2021 First Decision: 28 Jan 2021 Revised: 7 Feb 2021 Accepted: 22 Feb 2021 Available online: 21 Dec 2021

Academic Editors: Roberta Magliozzi, Athanassios P. Kyritsis Copy Editor: Xi-Jun Chen Production Editor: Xi-Jun Chen

\begin{abstract}
In multiple sclerosis (MS), a relationship with viral infection has long been recognized, starting from clinical evidence of an association between infectious events and disease onset or relapse. Herpesviridae and human endogenous retroviruses (HERVs) are among the most studied viral families in MS. These exposures share the characteristic of being latent persisting infections with hidden or dormant phases that allow them to escape immune detection and reactivate upon exposure to several stimuli. Moreover, their preferential tropism for cells of the central nervous system (CNS) and immune system accounts for their plausible pathogenic role in neuroinflammation. Compartmentalized and persisting chronic inflammation within the CNS is a feature of MS, as compared with other forms of self-limiting demyelinating conditions. This has suggested the existence of a persistent agent (such as a latent virus) that sustains the pathogenic loop and determines consequent tissue damage, failure of reparative mechanisms, and accumulation of neurological deficits. This review aims to survey the literature on the relationship between viruses and MS, with special reference to the levels of complexity in the loop that can modify disease risk, namely non-genetic risk factors (including viral components) that interact with each other and with genetic variants, with possible effects on both the host and viral genome. We will also review
\end{abstract}

The Author(s) 2021. Open Access This article is licensed under a Creative Commons Attribution 4.0 International License (https://creativecommons.org/licenses/by/4.0/), which permits unrestricted use, sharing adaptation, distribution and reproduction in any medium or format, for any purpose, even commercially, as long as you give appropriate credit to the original author(s) and the source, provide a link to the Creative Commons license, and indicate if changes were made. 
the latest advances in therapeutic targeting virus-induced dysregulations in MS.

Keywords: Epstein-Barr virus, herpesvirus, human herpesvirus 6, human endogenous retroviruses, multiple sclerosis, neuroinflammation, neurodegeneration

\section{INTRODUCTION}

Emerging data show a correlation between viral infection and neurodegenerative disease ${ }^{[1]}$. One current hypothesis considers the role of inflammation caused by viral infections in sustaining neuronal dysfunction and propagating neurodegeneration ${ }^{[2]}$. Viruses can induce brain damage by directly infecting the central nervous system (CNS) or through the resulting inflammatory response. Neurotrophic viruses such as herpesviruses and polyomaviruses can overcome host protective immunological mechanisms and enter the CNS, where they can elicit acute cell dysfunction, remain silent, or latently activate in infected cells over time. Through other indirect mechanisms, they can bring about lymphocyte activation and the subsequent release of proinflammatory cytokines that trigger neurodegeneration and affect cell-specific functions ${ }^{[3]}$. These mechanisms may be exacerbated by conditions of cell vulnerability due to disease-associated genetic variants ${ }^{[4]}$. Viruses have recently been associated with neurodegenerative diseases, such as Alzheimer's disease $(\mathrm{AD})^{[1,5-7]}$ and Parkinson's disease $(\mathrm{PD})^{[8,9]}$, where the presence of an inflammatory component in the pathogenic loop has only recently been recognized. Although these mechanisms linked to viral roles remain hypothetical and are still being investigated in classical neurodegenerative diseases, in multiple sclerosis (MS) the relationship with viral infection or viral components has long been recognized, starting from clinical evidence of an association between infectious events and disease onset or relapse.

Many viruses have been associated with MS over time with variable levels of evidence. In Table 1, we summarize data on viruses that have a controversial association with MS. Evidence regarding the possible role of these viruses as contributors to MS development is inconsistent, and for some of them a protective role was even suggested [Table 1]. Two virus families, whose role as risk exposures for MS have received the most plausible and convincing support, are Herpesviridae and human endogenous retroviruses (HERVs). Though the mechanisms through which these exposures contribute to MS etiopathogenesis are still being investigated, the two families have shown a consistent association with MS, which make them at least biomarker candidates of disease progression and therapy outcome. Herpesviridae and HERVs share the characteristic of being latent persisting infections with a hidden, inactive, or dormant phase that allows a potential pathogen to escape immune detection and reactivate upon exposure to several stimuli. Their preferential tropism for cells of the CNS and immune system accounts for their potential pathogenic role in neuroinflammation, whereby most pathological events remain compartmentalized within the CNS, mediating the persistence of chronic inflammation and the accumulation of neurological deficits. Among Herpesviridae, Epstein-Barr virus (EBV) and human herpesvirus 6 (HHV-6) prevail in several pathological and sero-epidemiological studies, while HERV-H/F and HERV-W families have been found to be MSassociated retroviruses (MSRVs).

Convergent evidence points to the role of EBV in neuroinflammation. Common patterns were observed in the epidemiology of infectious mononucleosis (IM) and $\mathrm{MS}^{[10,11]}$. MS risk is about 2-3 folds higher among individuals with a clinical history of IM, as compared with those without a history ${ }^{[12,13]}$. Compelling evidence has demonstrated that individuals who are not infected with EBV rarely, if ever, develop $\mathrm{MS}^{[3]}$. In a longitudinal study based on the Department of Defense Serum Repository, which contains samples from over 7 million young adults, individuals who were EBV-seronegative at baseline did not develop MS symptoms until at least several months after EBV seroconversion ${ }^{[14]}$. The high EBV seroprevalence in 
Table 1. Viruses with controversial associations with multiple sclerosis

\begin{tabular}{|c|c|c|c|}
\hline Virus & Ref. & Evidence for & Evidence against \\
\hline VZV & {$[98,111-117]$} & $\begin{array}{l}\text { - Acquired earlier in life by MS patients } \\
\text { - High seroprevalence of VZV antibodies in the CSF of MS } \\
\text { patients } \\
\text { - VZV restricted to MS clinical relapse period in PBMCs } \\
\text { - VZV reactivation could act as a trigger in MS disease onset } \\
\text { and may trigger immune-mediated demyelination processes }\end{array}$ & $\begin{array}{l}\text { - Absence of VZV DNA in the serum and CSF of MS } \\
\text { patients }\end{array}$ \\
\hline TTMV & {$[118,119]$} & $\begin{array}{l}\text { - Clonally expanded T cells from the CSF of MS patients } \\
\text { recognize viral motifs }\end{array}$ & $\begin{array}{l}\text { - No difference between MS and healthy subjects in } \\
\text { the level of TTMV infection }\end{array}$ \\
\hline CMV & {$[120-124]$} & $\begin{array}{l}\text { - T cells specific for CMV- elicited inflammation and worse } \\
\text { demyelination in MS animal models } \\
\text { - CMV has been found in demyelinating plaques and in the } \\
\text { CSF of MS patients } \\
\text { - Enrichment of CMV-specific CD8+ T cells in chronic } \\
\text { inflammatory lesions of the MS brain }\end{array}$ & $\begin{array}{l}\text { - CMV infection is associated with anti- } \\
\text { inflammatory activities, which could lead to a less } \\
\text { severe disease course } \\
\text { - CMV infection acquired during childhood reduced } \\
\text { the risk of developing MS or CIS in subjects up to } 18 \\
\text { years }\end{array}$ \\
\hline Measles & {$[125,126]$} & $\begin{array}{l}\text { - Measles antibody titers were significantly higher in blood } \\
\text { samples of MS than in control cases } \\
\text { - Higher levels of measles antibodies in CSF were found in } \\
\text { more disabled patients with a malignant disease course }\end{array}$ & $\begin{array}{l}\text { - No correlation was found between the presence } \\
\text { and level of serum anti-measles antibodies and anti- } \\
\text { MBP T cell activity } \\
\text { - The measles vaccination is not associated with MS }\end{array}$ \\
\hline Rubella & {$[127,128]$} & $\begin{array}{l}\text { - Rubella virus multiplies to low titer in glial cell cultures } \\
\text { derived from rats, and induces damage to oligodendrocytes } \\
\text { and myelin }\end{array}$ & - No evidence \\
\hline Coronavirus & [129] & $\begin{array}{l}\text { - Some coronaviruses are neurotropic and disrupt the blood- } \\
\text { brain barrier, causing immune-mediated demyelinating-like } \\
\text { lesions in rodents }\end{array}$ & - No evidence \\
\hline HSV-1 & [130-132] & - HSV-1 antibodies were found in the CSF of MS patients & $\begin{array}{l}\text { - Prior HSV-1 immunity could be protective against } \\
\text { MS }\end{array}$ \\
\hline
\end{tabular}

CIS: Clinically isolated syndrome; CMV: cytomegalovirus; CSF: cerebrospinal fluid; HSV-1: herpes simplex virus type 1; MBP: myelin basic protein; MS: multiple sclerosis; PBMCs: peripheral blood mononuclear cells; TTMV: torque teno virus; VZV: varicella-zoster virus.

pediatric MS confirms the peculiar role of EBV with respect to other exposures for MS development ${ }^{[15]}$.

The evidence of EBV-infected B cells in post-mortem brains of MS cases remains a controversial point ${ }^{[16-18]}$. The recent success of $B$ cell depleting therapies in relapsing-remitting and progressive forms of MS was regarded as indirect evidence that targeting EBV could improve disease course, since memory B cells harbor latent virus infection ${ }^{[19]}$. A pilot trial with in vitro expanded autologous EBV-specific T cell therapy directly tested the hypothesis that targeting EBV could be beneficial in progressive $\mathrm{MS}^{[20]}$.

Another herpesvirus associated with neuroinflammation is HHV-6, a neurotropic virus that may be commensal at a low number of copies in normal brains, but was reported to be enriched and more active in MS lesions ${ }^{[21]}$. A proposed association between HHV-6 and MS was first made in the early nineties with a histopathological study showing increased detection of HHV-6 DNA and proteins within MS plaques and specifically within oligodendrocytes as compared with control tissue ${ }^{[22]}$. In addition, anti-HHV-6 antibody titers in the serum of MS patients were found to be higher than in a cohort of healthy controls ${ }^{[23]}$. To explain how HHV-6 might act as a co-factor agent in MS, several hypotheses have been and are being explored, namely molecular mimicry, virus inhibition of the proliferation and viability of oligodendroglial cells, failure of myelin repair, and bystander effects.

HERV persists after ancestral retroviral infections, constituting up to $8 \%$ of the entire genome. Its presence is the result of a co-evolutionary process favoring a trade-off between pathogenic potential (usually kept at bay by several hereditary and environmental countermeasures, as well as by their incompetence or silenced coding potential) and benefits from some HERV functionalities. MSRV was first described by Perron et al. ${ }^{[24]}$ in 1997, when this group isolated the retroviral sequence from the meningeal and EBV- 
immortalized B cells of MS patients. The same sequence was also detected in non-cellular RNA from the plasma and cerebrospinal fluid (CSF) of untreated patients. Over the next decades, MSRV was consistently found in tissues from MS patients and the dynamics of MSRV gene expression proved to parallel and predict disease phases, MS progression, and therapy outcome ${ }^{[25]}$. Research is currently focused on the molecular aspects that determine HERV reactivation in response to exogenous and genetic MS risk factors and on antiretroviral treatments active against disease progression.

In the next sections, we survey the latest results on the relationship between the viruses (herpesviruses and HERV) and neuroinflammation, and discuss the potential identification of new virus-related biomarkers and therapeutic targets for an etiologic therapy against MS.

\section{HERPESVIRUSES AND NEUROINFLAMMATION EBV}

Herpesviruses, both those with tropism for nerve cells as well as those that preferentially infect lymphocytes, are widely associated with neurological disease. The most meaningful example is represented by EBV, a herpesvirus that infects epithelial cells by establishing a lytic (replicative) phase followed by a latent phase in which it persists within B lymphocytes. In some circumstances, the latency phase can be disrupted and the virus can shift into a replicative phase that allows its propagation ${ }^{[26]}$.

Many epidemiological, clinical, and laboratory studies support the involvement of EBV infection in MS neuroinflammation, but we still do not know the mechanisms through which the virus may contribute to disease development ${ }^{[27]}$. Among the attempts to clarify these mechanisms, our group and others ${ }^{[28-30]}$ have observed that the humoral immune response in MS against EBNA1 (Epstein-Barr nuclear antigen 1) targeted an immunodominant epitope that was recognized by IgG during IM and was subdominant in normal people ${ }^{[31]}$. This finding suggests a dysfunctional immune response to EBV primary infection that persists (instead of weaning, as in healthy subjects) in MS patients, and, notably encompasses an EBNA1 sequence that shares similarities with B-crystallin and anoctamin 2 (ANO2), both candidate autoantigens in $\mathrm{MS}^{[32,33]}$. It is plausible that the 2-to-3-fold increase in MS risk in people with a clinical history of IM (which usually occurs in late primary infection) may be included in the general 30 -fold increased MS risk that is associated with greater and dysfunctional immune response to EBNA1. In the context of an altered immune response to EBV in MS, it has been observed that T lymphocytes that keep the infection under control display an exhausted phenotype in the periphery and CNS of MS patients ${ }^{[34,35]}$. These data, along with evidence of antibodies against specific EBV proteins found in oligoclonal bands ${ }^{[3,3,3]}$, suggest the presence of an antiviral response within the CNS and raise the possibility of repeated "nonproductive" EBV reactivations. Further studies are needed to determine whether this altered interplay between EBV and antiEBV immune response is the cause of direct and indirect damage to neuronal tissues in MS.

Another level of complexity in the virus-host interplay is represented by the respective genomic variability. Single nucleotide polymorphisms (SNPs) have been associated with MS over time, and increasing evidence on this topic has been obtained thanks to genome-wide association studies ${ }^{[38-40]}$. This high-throughput approach led to the discovery (and in some cases confirmation) of SNPs located in DNA sequences coding for proteins or regulatory regions with a potential impact on gene expression and protein-protein interactions $s^{[41]}$. In this context, we proposed an interactome approach ${ }^{[41,42]}$ due to the complexity of interactions between genetic and non-genetic factors (mainly viral infections). Interactomes are defined as groups of genes coding for human proteins interacting with specific environmental factors (i.e., viruses). Our hypothesis is that SNPs within genes belonging to a specific interactome could affect virus-host interactions. In our previous work, we measured the enrichment of MS-associated genetic variants in 
genomic regions coding for proteins interacting with environmental factors and possibly influencing interactions. Among others, the EBV interactome was significantly associated with MS and was confirmed to significantly contribute to disease risk $^{[42]}$. This finding, and our ensuing reports on specific EBV genotypes that were correlated with MS status ${ }^{[3,44]}$, led us to hypothesize that the interaction between humans and viruses can be affected by the rate of variability of both genomes. Specifically, we studied Epstein-Barr nuclear antigen 2 (EBNA2) and found two intriguing peculiarities of this gene: single nucleotide variants within the coding sequence identified an allele that was frequently associated with $\mathrm{MS}^{[43]}$. This allele codes for a protein with binding motifs that were found to be enriched on human genomic regions containing MS-associated genetic variants ${ }^{[45]}$. This interplay could be relevant for MS pathogenesis since EBNA2 is one of the main viral transactivators driving the EBV latency phase in B lymphocytes. This protein acts on both viral and cellular gene promoters/enhancers through obligatory interactions with host cell transcription factors ${ }^{[46-48]}$. In such a complex interplay between EBNA2 and host cell factors, we hypothesize that the bias of EBNA2 allelic frequency found in MS patients can cause quantitative differences in EBNA2-dependent dysregulation of host cell gene expression ${ }^{[49,50]}$. Notably, data from other groups also support this hypothesis ${ }^{[51,52]}$, demonstrating a central role of EBNA2 DNA binding in regulating the immune response in MS and other autoimmune diseases.

To obtain experimental evidence of the in vivo role of EBV in MS development, several studies used experimental autoimmune encephalomyelitis (EAE), an accepted murine model of MS. Since EBV only infects humans, a murine gamma herpesvirus $68(\gamma \mathrm{HV}-68)$ that shares most of its genomes with EBV was considered. EBV and $\gamma \mathrm{HV}-68$ are similar in terms of cell tropism, latency, transformation potential, and elicited immune response features. With this model, Casiraghi et al. ${ }^{[53]}$ demonstrated that mice latently infected with $\gamma \mathrm{HV}-68$ developed more severe EAE and showed a change in the polarization of induced myelin-specific $\mathrm{T}$ cell response toward a potent Th1 response, with a decrease in peripheral Treg frequencies. Márquez et al. ${ }^{[54]}$ showed that the enhanced disease observed in $\gamma \mathrm{HV}-68$ latently-infected mice depended on maintaining the latent life cycle of the virus, and this was strongly associated with pSTAT1 and CD40 upregulation of uninfected $\mathrm{CD} 11 \mathrm{~b}+\mathrm{CD} 11 \mathrm{c}+$ cells, which in turn enhanced activation and CNS infiltration of CD8+ T cells. The same group recently reported that B cells latently infected by $\gamma \mathrm{HV}-68$ are indispensable in EAE enhancement, providing experimental support to the recent important impact that $\mathrm{B}$ cell-depleting approaches were found to have on MS cours $\mathrm{e}^{[55]}$. Regarding B cell role in MS pathophysiology, other evidence was obtained in marmoset EAE, the non-human primate model of MS. CalHV3 is the marmoset equivalent of human EBV, and Jagessar et al. ${ }^{[56]}$ used this model to show that virus-transformed B cells could have a crucial role in the pathogenesis of the marmoset EAE model. Finally, a recent work showed that EBV infection of humanized mice reconstituted with human immune systems positive for HLA-DR15 (the main genetic risk factor for MS) led to T cell hyperactivation and less efficient viral control, providing experimental in vivo support to the synergy between EBV infection and genetic predisposition to MS development ${ }^{[57]}$.

\section{HHV-6}

HHV-6 was discovered in 1988 and consists of two subtypes, HHV-6A and HHV-6B, both of which are prevalent in the normal population. Like other herpesviruses, HHV-6A/B establishes a lifelong latent infection in the host. The viral genome usually persists as an extrachromosomal episome, but HHV-6 can also integrate into host cell chromosomes. In addition to integrating into somatic cell chromosomes, HHV$6 \mathrm{~A}$ and $\mathrm{B}$ can also integrate into the chromosomes of germ line cells, a condition referred to as chromosomally integrated HHV-6 (iciHHV-6), which has an estimated prevalence of $0.6 \%-1 \%$ in the general population. HHV -6 is a neurotropic virus that also has lymphotropic and immunomodulating properties. For cellular entry, HHV-6 uses the complement regulatory receptor CD46, which is expressed in adult oligodendrocytes, astrocytes, and microglial cells. These features make it an excellent candidate to 
mediate pathogenic processes in MS.

Several studies showed that MS patients have increased titers of serum antibodies directed against HHV$6^{[58]}$. In particular, MS patients presented high prevalence of antibodies against U94/REP, a latency protein of HHv6, compared to healthy control (seroprevalence $51.47 \%$ vs. $28.57 \%$ and mean titer of positive samples 1:248 vs. $1: 110 ; P=0.0005)^{[59,60]}$. These results are in line with a recent study by Engdahl et al. ${ }^{[61]}$, who measured, using a novel multiplex serological assay, IgG reactivity against the immediate-early protein 1 from HHV-6A (IE1A) and HHV-6B (IE1B) in a MS cohort. IgG response against IE1A was positively associated with MS $\left(\mathrm{OR}=1.55, P=9 \times 10^{-22}\right)$ and an interaction was observed between IE1A and EBV antibody responses for MS risk.

While previous studies demonstrated differences between patients and controls (see ntroduction), more recent studies are aimed at correlating viral biomarkers with MS phenotypes or courses. Knox et al. ${ }^{[62]}$ demonstrated that MS patients testing positive for HHV- 6 by rapid culture assay tended to be younger and have a shorter disease duration, supporting a potential role of HHV-6 in triggering early autoimmune processes in the CNS. Several groups postulate that HHV- 6 antibodies could correlate with MS clinical course. A study on a Tasmanian cohort found anti-HHV-6 IgG titer to be a significant predictor of relapse risk $^{[63]}$, while other studies have shown that decreased HHV-6 antibody titers correlated with fewer relapses and less disease progression ${ }^{[64]}$. Similar results were reported by Berti et al. ${ }^{[65]}$, who used sensitive nested PCR techniques and found HHV-6 DNA more frequently in serum samples from MS patients in clinical exacerbation than from MS patients in clinical remission. The same group reported that HHV-6 viral load and anti-HHV -6 antibody titers in blood samples of MS patients could predict therapeutic response to disease-modifying therapies ${ }^{[64]}$.

Many recent works have aimed to clarify the mechanisms by which HHV-6 may be involved in MS development. While a bystander effect could be attributed to many neurotropic viruses, other pathogenic actions seem more specific for a pathogenic role of HHV-6. This virus could play a role as an initiator or amplifier of inflammatory lesions in MS patients. CD8+ T cell-mediated response to HHV-6-infected cells of the CNS may induce a pro-inflammatory milieu, with tissue damage and a subsequent release of sequestered antigens that in turn activate self-reactive lymphocytes, amplifying auto-aggressive immune responses ${ }^{[66]}$. Moreover, the fact that HHV-6A uses CD46 as a cellular receptor could increase activation of the complement system. Alvarez-Lafuente et al. ${ }^{[6]}$ demonstrated that CD46 expression was upregulated in patients with MS with HHV-6 infection. The latent infection of astrocytes, which are crucial for maintaining extracellular glutamate levels to prevent excitotoxic damage of surrounding nerve cells, may play a pathogenic role by amplifying the immune-mediated process. HHV-6-infected astrocytes demonstrated an impaired ability to uptake glutamate, which was associated with decreased expression of the glial glutamate transporter EAAT-2 ${ }^{[68]}$. Dysregulation of glutamate levels can trigger excitotoxic death of oligodendrocytes through overactivation of AMPA and kainate receptors and subsequent oligodendroglial death ${ }^{[69]}$.

A more HHV-6-specific pathogenic mechanism includes molecular mimicry. It was demonstrated that protein $\mathrm{U}_{24}$ (an integral membrane protein of HHV-6) shares a sequence of seven amino acids with myelin basic protein, a main component of the myelin sheath, raising the possibility that $\mathrm{T}$ cells may be activated by the HHV - 6 epitope and then cross-recognize myelin basic protein, becoming pathogenic ${ }^{[70,71]}$. Crossreactivity with myelin antigens could contribute to direct oligodendrocyte damage in $\mathrm{MS}^{[7]}$. Another deleterious effect of HHV-6 latent infection of the CNS was demonstrated by Kong et al. ${ }^{[72]}$, who found a negative effect on oligodendrocyte viability and function. Among the two viral variants, HHV-6 A is more powerful in reducing oligodendrocyte proliferation than variant B. Notably, HHV-6A DNA is found with 
higher frequency in the serum of MS patients ${ }^{[67,72]}$. The HHV-6 protein U94, which is involved in latent state maintenance and is a target of humoral response in MS patients ${ }^{[59]}$, could play a role in the myelin repair failure that invariably occurs as MS progresses. In fact, a recent in vitro study focused on the effect of the HHV-6A latency protein U94 on oligodendrocyte progenitor cells (OPCs) derived from fetal brains and cultured or transplanted in mouse brains. The authors found impaired OPC migration in cells expressing U94 that were not yet capable of repairing myelin damage ${ }^{[59,60]}$. Finally, Gardell et al.$^{[73]}$ reported that CNS penetration by replicating HHV-6 variant A has the potential to initiate programmed cell death of oligodendrocytes, glial cells, and neurons. In particular, glial cell apoptosis could be a primary event in the autoimmune cascade in MS and other demyelinating disorders.

In vivo experiments to support the role of HHV-6 in MS development have been difficult to implement because of the difficulty in establishing animal models of latent infection. In fact, rodents lack widespread CD46 expression, the main cellular receptor for HHV-6 entry. Marmosets have proven to be a good EAE model to test the role of HHV-6 in disease pathogenesis. Using intranasal routes of HHV-6 inoculation in marmosets, Leibovitch et al. ${ }^{[21]}$ showed that latent asymptomatic infection accelerated subsequent neuroinflammation in the nonhuman primate model of MS. The underpinning findings were the expansion of a proinflammatory CD8 subset and the presence of HHV-6 viral antigens in brain lesions of virus/EAE marmosets, which is consistent with previous findings on HHV-6 localizations in MS brain lesions.

\section{MS-RELATED RETROVIRUSES AND NEUROINFLAMMATION}

HERVs are classified into three classes and further divided into 31 families. To define each family, a letter is added to HERV (e.g., HERV-W, HERV-K, HERV-H, etc.), which identifies transfer RNA (tRNA) specificity of the binding site ${ }^{[7]}$. The HERV genome is the same as exogenous retroviruses and encodes four viral proteins: Gag (matrix and retroviral core), Pol (reverse transcriptase), Pro (integrase), and Env (envelope). This part of the viral genome is delimited by two long terminal repeat regions, which contain the regulators (enhancers and promoters) of HERV gene expression. Epigenetic control is fundamental for the transcriptional activity of HERV sequences. Indeed, the capability of HERV genes to become active is linked to the preservation of functional long terminal repeat and the absence of mutations that disrupt their open reading frames ${ }^{[75]}$. HERVs are usually highly defective since they have accumulated various mutations and recombination through evolution: between $7 \%$ and $30 \%$ of all HERV sequences are transcriptionally active in the genome $\mathrm{e}^{[7]}$. This transcriptional activity seems to be limited to Env proteins that may be useful for the host: for example, HERV-W locus 7q21.2 produces a functional Env protein (Syncytin-1) involved in placental syncytiotrophoblast formation ${ }^{[76]}$. Dysregulated epigenetic control of $H E R V$ gene expression occurs in autoimmune, neurodegenerative, and chronic inflammatory diseases. Factors that typically influence $H E R V$ epigenetic control are viral infections, particularly Herpesviridae infections. This interaction is of particular interest in MS; both EBV and HHV-6 can awaken HERV sequences from their dormant state, whereas herpesviruses could be an initial trigger for HERV-W/MSRV-mediated pathogenic actions ${ }^{[75]}$. It has been suggested that viral risk factors interplay with each other, and in turn interact with other non-genetic and genetic etiological components of the host in a loop that eventually overcomes the threshold for disease development [Figure 1].

Since the first detection of HERVs in MS in the early $90 s^{[77]}$, different research groups have studied the possible correlation between the expression of these endogenous retroviruses and MS. Many studies have pointed to HERV-W as a main trigger of MS. In particular, HERV-W Env protein and its endogenous HERV-W Env homolog from chromosome 7q, renamed syncytin ${ }^{[78]}$, has been the viral protein most often detected in the serum/plasma and CSF of MS patients as compared with control groups. Moreover, several studies have demonstrated the presence of Env in macrophages and/or microglial cells in active plaques of 


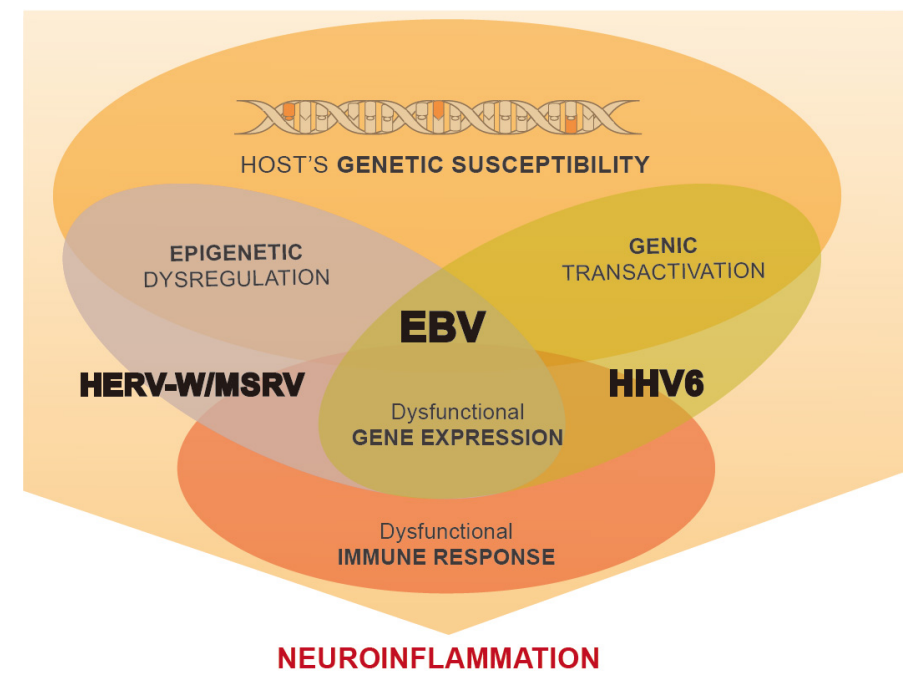

Figure 1. Schematic representation of the interplay between viral and genetic risk factors in MS. Virus-host interaction can be dysregulated in genetically predisposed subjects. The herpesviruses can induce a dysregulation of epigenetic control and a dysfunctional immune response leading to the reactivation of endogenous retroviruses. MS: Multiple sclerosis.

MS patients ${ }^{[79,80]}$.

A meta-analysis performed by Morandi et al.$^{[81]}$ showed a strong association between MSRV/ HERV-Wpol and MSRV/HERV-Wenv and MS. A high OR (22.66) was demonstrated using healthy blood donors as a control group for the env meta-analysis.

However, the major limitation of these meta-analysis was the relatively small population samples, all from European genetic groups with a very high risk of MS, such as the Sardinian population. Consequently, it is not clear that this relationship holds for all ethnic groups.

To overcome this issue a recent study examined the RNA expression in peripheral blood of HERV-W of MS patients and healthy control from two ethnic groups with very different risk rates of MS, from UK with an MS risk rate of 108/100,000 and from the republic of Tatarstan, with a mixed Russian and Tartar population which have an MS risk rate of 21-31/100,000. The Russian population demonstrated higher level of expression of MSRV compared to the British population in both healthy and MS groups, but with higher expression levels in MS patients than healthy patients ${ }^{[82]}$.

The potential pro-inflammatory and immunopathogenic effects of MSRV Env seem to be due to the activation of Toll-like receptor (TLR) 4 and its co-receptor CD14 expressed on monocytes and endothelial cells $^{[83,84]}$, leading to the production of pro-inflammatory cytokines, such as interleukin-1 $\beta$ (IL-1 $\beta$ ), interleukin-6 (IL-6), and tumor necrosis factor- $\alpha(\text { TNF- } \alpha)^{[s 5]}$. The activation of TLR4 on endothelial cells induces ICAM- 1 expression, which attracts T cells from the bloodstream to the CNS. As T cells arrive in the CNS, Env protein can interact with a $\mathrm{T}$ cell receptor region, which is independent of the antigen-binding site, activating multiple clones irrespective of their antigen specificity. The function of Env protein as a superantigen, together with its pro-inflammatory effects on microglia, could mediate a vicious circle leading to uncontrolled autoreactive cell expansion and massive secretion of pro-inflammatory cytokines in the $\mathrm{CNS}^{[75]}$. Moreover, the Env protein co-localizes with OPCs in normal-appearing white matter of MS patients. The activation of TLR4 expressed on OPCs determines the production of pro-inflammatory 
cytokines and inducible nitric oxide synthase (iNOS), which in turn results in nitro-tyrosine groups and changes in myelin protein expression ${ }^{[86]}$. These negative effects of the HERV-W Env protein on OPC may interfere with myelin repair, causing defective remyelination and contributing to MS progression ${ }^{[79,87]}$. Several studies postulate that HERV could be implicated not only in triggering mechanisms underlying MS development, but also in disease progression through the maintenance of a chronic inflammatory state.

Longitudinal studies evidenced that the presence of MSRV/HERV-W in the CSF of patients with early MS is linked to a greater relapse rate, a worse Expanded Disability Status Scale (EDSS) score, and a higher probability to reach secondary progression ${ }^{[87]}$. Patients affected by optic neuritis, a possible prodromal MS condition, who had high MSRV positivity in blood and CSF, showed a higher rate of conversion to MS over the next 20 months. Of note, MSRV gene expression diminishes when patients undergo therapy. Some studies have demonstrated a significant reduction in viremia in patients treated with interferon beta, natalizumab, and fingolimod, suggesting a role of HERV-W/MSRV as a biomarker for MS course and therapy outcome $e^{[25]}$.

HERV-W/MSRV has been studied as a potential therapeutic target due to its potential role in MS pathophysiology. In this context, a recombinant DNA-derived humanized antibody of IgG4/kappa subclass, GNbAC1, was developed. GNbAC1 selectively binds to the surface domain of the MSRV-Env protein with an affinity (KD) of $2.2 \mathrm{Nm}$. It acts by neutralizing MSRV TLR4 binding potential ${ }^{[84,88]}$. Consequently, GNbAC1 could simultaneously block the pathological inflammation process and restore the remyelination process in MS patients. The biological activity of this monoclonal antibody was first determined with in vitro assays and with experimental allergic encephalitis (EAE) models induced by MSRV-Env ${ }^{[83]}$. It is now being investigated as an MS treatment, especially in the progressive stage where a defective remyelination process prevails $^{[89]}$.

In humans, GNbAC1 is administered intravenously every 4 weeks. To date, two randomized controlled trials (phase IIa and phase IIb) have been conducted on MS patients ${ }^{[0]}$. The phase IIa study included 12 subjects affected by relapsing-remitting MS. Considering the small sample size, no marker of efficacy was analyzed. The safety endpoint was met since no adverse events were reported and only one patient presented a new lesion at MRI scan after 12 months of treatment ${ }^{[91]}$. The phase IIb study (CHANGE-MS) (ClinicalTrials.gov Identifier: NCT02782858) was a double-blind placebo-controlled trial conducted over 24 months that recruited 270 relapsing-remitting MS patients with active disease. The primary endpoint was disease activity at MRI expressed as the cumulative number of gadolinium-enhancing T1 lesions on brain MRI (time frame: week 12-24). The secondary endpoints also considered brain atrophy. There were no significant changes in MRI activity, clinical relapses, or brain volume loss in GNbAC1-treated cohorts. However, predefined analyses were also performed and a reduction in new contrast-enhancing lesions was observed in active patients treated with the highest dose $v s$. those treated with placebo ${ }^{[2]}$. Some secondary measures of tissue damage were better in the treated group than in the placebo ${ }^{[00]}$. Currently, a possible neuroprotective effect of GNbAC1 cannot be ruled out and further studies are needed to confirm a possible therapeutic effect of this monoclonal antibody. An open-label long-term extension of CHANGE-MS for 96 weeks is ongoing (ANGEL-MS) to evaluate long-term effects of this approach (ClinicalTrials.gov identifier: NCT03239860). In this context, a recent work showed that HERV-W Env directly fuels microglia-induced axonal damage in MS, and this result seems to offer an explanation for the apparent neuroprotective effect of approaches based on antibody-mediated neutralization of HERV-W Env ${ }^{[93]}$. 


\section{CONCLUSION}

Two main lines emerge from the studies reported in the previous sections: (1) the possible identification of new MS-specific inflammatory biomarkers; and (2) the development of therapeutic approaches, possibly expanding current disease-modifying therapies to underlying driver(s) of disease.

Concerning biomarkers, EBNA2 variants have been described as good predictors of MS risk ${ }^{[43]}$ and may plausibly represent a biomarker of disease course or disease-modifying therapy response. HHV-6 serology has been variably correlated to MS phase and course (reviewed in Leibovitch and Jacobson ${ }^{[94]}, 2014$ ). A recent work based on a novel multiplex serological assay measuring IgG reactivity against the immediateearly protein 1 from HHV-6A (IE1A) and HHV-6B (IE1B) seems to provide a reliable biomarker to predict MS risk ${ }^{[61]}$. New and confirmative studies are needed to verify whether these approaches may help in MS management. MSRV gene expression showed a good correlation with MS course and may be a promising biomarker candidate. Nonetheless, the lack of a standardized and optimized detection method and the different expression levels in diverse populations constitute major obstacles to be overcome ${ }^{[74]}$. Stronger evidence is needed to understand the potential impact of MSRV-based assays on clinical practice.

Implementing new vaccines or antiviral therapies capable of preventing or etiologically targeting modifiable MS risk factors may be of interest in disease management. Important ongoing research is focusing on antiEBV approaches, also taking into account its pathogenic role in several cancers and post-transplant lymphoproliferative disorders ${ }^{[5]}$. Phase II vaccine trials are under way and have shown preliminary benefits ${ }^{[96]}$, and an experimental approach to improve the immunogenicity of potential vaccinations has been reported ${ }^{[97,98]}$. Besides vaccination, other innovative approaches are being investigated to block EBV and other herpesvirus infections. Small molecule inhibitors of EBNA1 DNA binding or novel editing by CRISPR/Cas9 of the viral genome are of special interest because they are aimed at latent infection, which is likely to be important in MS etiopathogenesis ${ }^{[99,100]}$.

Antiviral compounds (especially in disorders mediated by herpesviruses) have already been tried in MS patients without significant results. The future of this approach seems to rely on antiretroviral treatments, which have been inspired by some reports of benefits in treated HIV-positive patients also affected by $\mathrm{MS}^{[101-104]}$. An open-label phase II trial of the anti-retroviral raltegravir in $60 \mathrm{HIV}$-negative patients with relapsing-remitting MS showed no benefit ${ }^{[105]}$. An HIV-negative person with MS treated with a combination of lamivudine and zidovudine, which is used in the treatment of HIV infection, was recently reported to show clear benefits from this treatment, which may also have anti-EBV action ${ }^{[106,107]}$. The prodrug tenofovir, used clinically for HIV prevention, was recently reported as an inhibitor of EBV ${ }^{[108]}$. Among antiretroviral therapies, the monoclonal antibody GNbAC1, which is specific for MSRV-Env, is currently under investigation, and the possibility of antagonizing HERV and EBV, which are known to interact with each other, especially in B cells (see above), is an intriguing area of investigation in preclinical studies ${ }^{[109]}$.

Long-term perspectives may include approaches that consider the interaction between viruses and other risk factors of MS neuroinflammation, including the modification of known risk factors (such as vitamin D insufficiency, smoking exposure, and body mass index disorders), which has been shown to improve viral biomarkers ${ }^{[110]}$, or approaches based on pathogenic interactions between viral exposure and genetic susceptibility to MS, which may alter the liability threshold for the disease and represent an integral etiologic approach to MS therapy ${ }^{[41]}$. 


\section{DECLARATIONS}

\section{Authors' contributions}

Literature research and summarizing references: Bigi R, Buscarinu MC, Marrone A, Ballerini C, Angeloni B, Rinaldi V

Drafting the manuscript: Mechelli R, Romano C, Reniè R, Ristori G

Creating tables and figures: Mechelli R, Reniè R, Bellucci G

Discussing the drafting of the manuscript and revising the manuscript: Mechelli R, Romano S, Ristori G, Salvetti M

Read and approved the final manuscript: Salvetti M, Ristori G

\section{Availability of data and materials}

Not applicable.

\section{Financial support and sponsorship}

This work was supported by the Italian Multiple Sclerosis Foundation (FISM, grant number 2017/R/18 to RM) and by Ricerca corrente to IRCCS San Raffaele Pisana to RM.

\section{Conflicts of interest}

No authors declare any conflicts of interest.

\section{Ethical approval and consent to participate}

Not applicable.

\section{Consent for publication}

Not applicable.

\section{Copyright}

(c) The Author(s) 2021.

\section{REFERENCES}

1. Sa AC, Madsen H, Brown JR. Shared molecular signatures across neurodegenerative diseases and herpes virus infections highlights potential mechanisms for maladaptive innate immune responses. Sci Rep 2019;9:8795. DOI PubMed PMC

2. Deleidi M, Isacson O. Viral and inflammatory triggers of neurodegenerative diseases. Sci Transl Med 2012;4:121ps3. DOI PubMed PMC

3. Chen WW, Zhang X, Huang WJ. Role of neuroinflammation in neurodegenerative diseases (Review). Mol Med Rep 2016;13:3391-6. DOI PubMed PMC

4. Hamza TH, Zabetian CP, Tenesa A, et al. Common genetic variation in the HLA region is associated with late-onset sporadic Parkinson's disease. Nat Genet 2010;42:781-5. DOI PubMed PMC

5. Itzhaki RF. Herpes simplex virus type 1 and Alzheimer's disease: increasing evidence for a major role of the virus. Front Aging Neurosci 2014;6:202. DOI PubMed PMC

6. De Chiara G, Piacentini R, Fabiani M, et al. Recurrent herpes simplex virus-1 infection induces hallmarks of neurodegeneration and cognitive deficits in mice. PLoS Pathog 2019;15:e1007617. DOI PubMed PMC

7. Ezzat K, Pernemalm M, Pålsson S, et al. The viral protein corona directs viral pathogenesis and amyloid aggregation. Nat Commun 2019;10:2331. DOI PubMed PMC

8. Woulfe JM, Gray MT, Gray DA, Munoz DG, Middeldorp JM. Hypothesis: a role for EBV-induced molecular mimicry in Parkinson's disease. Parkinsonism Relat Disord 2014;20:685-94. DOI PubMed

9. Limphaibool N, Iwanowski P, Holstad MJV, Kobylarek D, Kozubski W. Infectious etiologies of parkinsonism: pathomechanisms and clinical implications. Front Neurol 2019;10:652. doi: 10.3389/fneur.2019. 652:00. DOI PubMed PMC

10. Warner HB, Carp RI. Multiple sclerosis etiology--an Epstein-Barr virus hypothesis. Med Hypotheses 1988;25:93-7. DOI PubMed

11. Ascherio A, Munger KL. Environmental risk factors for multiple sclerosis. Part I: the role of infection. Ann Neurol 2007;61:288-99. DOI PubMed

12. Thacker EL, Mirzaei F, Ascherio A. Infectious mononucleosis and risk for multiple sclerosis: a meta-analysis. Ann Neurol 2006;59:499-503. DOI PubMed

13. Nielsen TR, Rostgaard K, Nielsen NM, et al. Multiple sclerosis after infectious mononucleosis. Arch Neurol 2007;64:72-5. DOI 
PubMed

14. Levin LI, Munger KL, O'Reilly EJ, Falk KI, Ascherio A. Primary infection with the Epstein-Barr virus and risk of multiple sclerosis. Ann Neurol 2010;67:824-30. DOI PubMed PMC

15. Alotaibi S, Kennedy J, Tellier R, Stephens D, Banwell B. Epstein-Barr virus in pediatric multiple sclerosis. JAMA 2004;291:1875-9. DOI PubMed

16. Serafini B, Rosicarelli B, Franciotta D, et al. Dysregulated Epstein-Barr virus infection in the multiple sclerosis brain. $J$ Exp Med 2007;204:2899-912. DOI PubMed PMC

17. Willis SN, Stadelmann C, Rodig SJ, et al. Epstein-Barr virus infection is not a characteristic feature of multiple sclerosis brain. Brain 2009;132:3318-28. DOI PubMed PMC

18. Ascherio A, Bar-Or A. EBV and brain matter(s)? Neurology 2010;74:1092-5. DOI PubMed

19. Bar-Or A, Pender MP, Khanna R, et al. Epstein-Barr virus in multiple sclerosis: theory and emerging immunotherapies. Trends Mol Med 2020;26:296-310. DOI PubMed PMC

20. Pender MP, Csurhes PA, Smith C, et al. Epstein-Barr virus-specific T cell therapy for progressive multiple sclerosis. JCI Insight 2018;3:e124714. DOI PubMed PMC

21. Leibovitch EC, Jacobson S. Viruses in chronic progressive neurologic disease. Mult Scler 2018;24:48-52. DOI PubMed PMC

22. Challoner PB, Smith KT, Parker JD, et al. Plaque-associated expression of human herpesvirus 6 in multiple sclerosis. Proc Natl Acad Sci US A 1995;92:7440-4. DOI PubMed PMC

23. Friedman JE, Lyons MJ, Cu G, et al. The association of the human herpesvirus-6 and MS. Mult Scler 1999;5:355-62. DOI PubMed

24. Perron H, Garson JA, Bedin F, et al. Molecular identification of a novel retrovirus repeatedly isolated from patients with multiple sclerosis. The Collaborative Research Group on Multiple Sclerosis. Proc Natl Acad Sci U S A 1997;94:7583-8. DOI PubMed PMC

25. Dolei A. The aliens inside us: HERV-W endogenous retroviruses and multiple sclerosis. Mult Scler 2018;24:42-7. DOI PubMed

26. Hislop AD, Taylor GS, Sauce D, Rickinson AB. Cellular responses to viral infection in humans: lessons from Epstein-Barr virus. Annu Rev Immunol 2007;25:587-617. DOI PubMed

27. Lünemann JD. Epstein-Barr virus in multiple sclerosis: a continuing conundrum. Neurology 2012;78:11-2. DOI PubMed

28. Sundström P, Nyström M, Ruuth K, Lundgren E. Antibodies to specific EBNA-1 domains and HLA DRB1*1501 interact as risk factors for multiple sclerosis. J Neuroimmunol 2009;215:102-7. DOI PubMed

29. Jafari N, van Nierop GP, Verjans GM, Osterhaus AD, Middeldorp JM, Hintzen RQ. No evidence for intrathecal IgG synthesis to Epstein Barr virus nuclear antigen-1 in multiple sclerosis. J Clin Virol 2010;49:26-31. DOI PubMed

30. Mechelli R, Anderson J, Vittori D, et al. Epstein-Barr virus nuclear antigen-1 B-cell epitopes in multiple sclerosis twins. Mult Scler 2011;17:1290-4. DOI PubMed

31. McClain MT, Rapp EC, Harley JB, James JA. Infectious mononucleosis patients temporarily recognize a unique, cross-reactive epitope of Epstein-Barr virus nuclear antigen-1. J Med Virol 2003;70:253-7. DOI PubMed

32. van Noort JM, van Sechel AC, Bajramovic JJ, et al. The small heat-shock protein alpha B-crystallin as candidate autoantigen in multiple sclerosis. Nature 1995;375:798-801. DOI PubMed

33. Tengvall K, Huang J, Hellström C, et al. Molecular mimicry between Anoctamin 2 and Epstein-Barr virus nuclear antigen 1 associates with multiple sclerosis risk. Proc Natl Acad Sci U S A 2019;116:16955-60. DOI PubMed PMC

34. Angelini DF, Serafini B, Piras E, et al. Increased CD8+ T cell response to Epstein-Barr virus lytic antigens in the active phase of multiple sclerosis. PLoS Pathog 2013;9:e1003220. DOI PubMed PMC

35. Cencioni MT, Magliozzi R, Nicholas R, et al. Programmed death 1 is highly expressed on CD8+ CD57+ T cells in patients with stable multiple sclerosis and inhibits their cytotoxic response to Epstein-Barr virus. Immunology 2017;152:660-76. DOI PubMed PMC

36. Cepok S, Zhou D, Srivastava R, et al. Identification of Epstein-Barr virus proteins as putative targets of the immune response in multiple sclerosis. J Clin Invest 2005;115:1352-60. DOI PubMed PMC

37. Pfuhl C, Oechtering J, Rasche L, et al. Association of serum Epstein-Barr nuclear antigen-1 antibodies and intrathecal immunoglobulin synthesis in early multiple sclerosis. J Neuroimmunol 2015;285:156-60. DOI PubMed

38. Sawcer S, Hellenthal G, Pirinen M, et al; International Multiple Sclerosis Genetics Consortium; Wellcome Trust Case Control Consortium 2. Genetic risk and a primary role for cell-mediated immune mechanisms in multiple sclerosis. Nature 2011;476:214-9. DOI PubMed PMC

39. International Multiple Sclerosis Genetics Consortium (IMSGC), Beecham AH, Patsopoulos NA, Xifara DK, et al. Analysis of immune-related loci identifies 48 new susceptibility variants for multiple sclerosis. Nat Genet 2013;45:1353-60. DOI PubMed PMC

40. Multiple Sclerosis Genetics Consortium. Multiple sclerosis genomic map implicates peripheral immune cells and microglia in susceptibility. Science 2019;365:eaav7188. DOI PubMed PMC

41. Mechelli R, Umeton R, Manfrè G, et al. Reworking GWAS data to understand the role of nongenetic factors in MS etiopathogenesis. Genes (Basel) 2020;11:97. DOI PubMed PMC

42. Mechelli R, Umeton R, Policano C, et al; International Multiple Sclerosis Genetics Consortium; Wellcome Trust Case Control Consortium; 2. A "candidate-interactome" aggregate analysis of genome-wide association data in multiple sclerosis. PLoS One 2013;8:e63300. DOI PubMed PMC

43. Mechelli R, Manzari C, Policano C, et al. Epstein-Barr virus genetic variants are associated with multiple sclerosis. Neurology 2015;84:1362-8. DOI PubMed PMC

44. Chiara M, Manzari C, Lionetti C, et al. Geographic population structure in Epstein-Barr virus revealed by comparative genomics. 
Genome Biol Evol 2016;8:3284-91. DOI PubMed PMC

45. Ricigliano VA, Handel AE, Sandve GK, et al. EBNA2 binds to genomic intervals associated with multiple sclerosis and overlaps with vitamin D receptor occupancy. PLoS One 2015;10:e0119605. DOI PubMed PMC

46. Zhou H, Schmidt SC, Jiang S, et al. Epstein-Barr virus oncoprotein super-enhancers control B cell growth. Cell Host Microbe 2015;17:205-16. DOI PubMed PMC

47. Lu F, Chen HS, Kossenkov AV, DeWispeleare K, Won KJ, Lieberman PM. EBNA2 drives formation of new chromosome binding sites and target genes for B-Cell master regulatory transcription factors RBP-jк and EBF1. PLoS Pathog 2016;12:e1005339. DOI PubMed PMC

48. Jiang S, Zhou H, Liang J, et al. The Epstein-Barr virus regulome in lymphoblastoid cells. Cell Host Microbe 2017;22:561-73. :e4. DOI PubMed PMC

49. Veroni C, Marnetto F, Granieri L, et al. Immune and Epstein-Barr virus gene expression in cerebrospinal fluid and peripheral blood mononuclear cells from patients with relapsing-remitting multiple sclerosis. J Neuroinflammation 2015;12:132. DOI PubMed PMC

50. Veroni C, Serafini B, Rosicarelli B, Fagnani C, Aloisi F. Transcriptional profile and Epstein-Barr virus infection status of laser-cut immune infiltrates from the brain of patients with progressive multiple sclerosis. J Neuroinflammation 2018;15:18. DOI PubMed PMC

51. Harley JB, Chen X, Pujato M, et al. Transcription factors operate across disease loci, with EBNA2 implicated in autoimmunity. Nat Genet 2018;50:699-707. DOI PubMed PMC

52. Liu X, Hong T, Parameswaran S, et al. Human virus transcriptional regulators. Cell 2020;182:24-37. DOI PubMed PMC

53. Casiraghi C, Shanina I, Cho S, Freeman ML, Blackman MA, Horwitz MS. Gammaherpesvirus latency accentuates EAE pathogenesis: relevance to Epstein-Barr virus and multiple sclerosis. PLoS Pathog 2012;8:e1002715. DOI PubMed PMC

54. Márquez AC, Horwitz MS. The role of latently infected B cells in CNS autoimmunity. Front Immunol 2015;6:544. DOI PubMed PMC

55. Márquez AC, Shanina I, Horwitz MS. Multiple sclerosis-like symptoms in mice are driven by latent $\gamma$ Herpesvirus-68 infected B cells. Front Immunol 2020;11:584297. DOI PubMed PMC

56. Anwar Jagessar S, Fagrouch Z, Heijmans N, et al. The different clinical effects of anti-BLyS, anti-APRIL and anti-CD20 antibodies point at a critical pathogenic role of $\gamma$-herpesvirus infected B cells in the marmoset EAE model. J Neuroimmune Pharmacol 2013;8:727-38. DOI PubMed

57. Zdimerova H, Murer A, Engelmann C, et al. Attenuated immune control of Epstein-Barr virus in humanized mice is associated with the multiple sclerosis risk factor HLA-DR15. Eur J Immunol 2021;51:64-75. DOI PubMed

58. Moore FG, Wolfson C. Human herpes virus 6 and multiple sclerosis. Acta Neurol Scand 2002;106:63-83. DOI PubMed

59. Ben-Fredj N, Ben-Selma W, Rotola A, et al. Prevalence of human herpesvirus U94/REP antibodies and DNA in Tunisian multiple sclerosis patients. J Neurovirol 2013;19:42-7. DOI PubMed

60. Caselli E, Boni M, Bracci A, et al. Detection of antibodies directed against human herpesvirus 6 U94/REP in sera of patients affected by multiple sclerosis. J Clin Microbiol 2002;40:4131-7. DOI PubMed PMC

61. Engdahl E, Gustafsson R, Huang J, et al. Increased serological response against human herpesvirus 6A is associated with risk for multiple sclerosis. Front Immunol 2019;10:2715. DOI PubMed PMC

62. Knox KK, Brewer JH, Henry JM, Harrington DJ, Carrigan DR. Human herpesvirus 6 and multiple sclerosis: systemic active infections in patients with early disease. Clin Infect Dis 2000;31:894-903. DOI PubMed

63. Simpson S, Taylor B, Dwyer DE, et al. Anti-HHV-6 IgG titer significantly predicts subsequent relapse risk in multiple sclerosis. Mult Scler 2012;18:799-806. DOI PubMed

64. Ortega-Madueño I, Garcia-Montojo M, Dominguez-Mozo MI, et al. Anti-human herpesvirus 6A/B IgG correlates with relapses and progression in multiple sclerosis. PLoS One 2014;9:e104836. DOI PubMed PMC

65. Berti R, Brennan MB, Soldan SS, et al. Increased detection of serum HHV-6 DNA sequences during multiple sclerosis (MS) exacerbations and correlation with parameters of MS disease progression. J Neurovirol 2002;8:250-6. DOI PubMed

66. Horwitz MS, Sarvetnick N. Viruses, host responses, and autoimmunity. Immunol Rev 1999;169:241-53. DOI PubMed PMC

67. Alvarez-Lafuente R, García-Montojo M, De las Heras V, Bartolomé M, Arroyo R. Clinical parameters and HHV-6 active replication in relapsing-remitting multiple sclerosis patients. J Clin Virol 2006;37 Suppl 1:S24-6. DOI PubMed

68. Fotheringham J, Williams EL, Akhyani N, Jacobson S. Human herpesvirus 6 (HHV-6) induces dysregulation of glutamate uptake and transporter expression in astrocytes. J Neuroimmune Pharmacol 2008;3:105-16. DOI PubMed

69. Matute C, Alberdi E, Domercq M, Pérez-Cerdá F, Pérez-Samartín A, Sánchez-Gómez MV. The link between excitotoxic oligodendroglial death and demyelinating diseases. Trends Neurosci 2001;24:224-30. DOI PubMed

70. Tejada-Simon MV, Zang YC, Hong J, Rivera VM, Zhang JZ. Cross-reactivity with myelin basic protein and human herpesvirus-6 in multiple sclerosis. Ann Neurol 2003;53:189-97. DOI PubMed

71. Cheng W, Ma Y, Gong F, et al. Cross-reactivity of autoreactive T cells with MBP and viral antigens in patients with MS. Front Biosci (Landmark Ed) 2012;17:1648-58. DOI PubMed

72. Kong H, Baerbig Q, Duncan L, Shepel N, Mayne M. Human herpesvirus type 6 indirectly enhances oligodendrocyte cell death. $J$ Neurovirol 2003;9:539-50. DOI PubMed

73. Gardell JL, Dazin P, Islar J, Menge T, Genain CP, Lalive PH. Apoptotic effects of Human Herpesvirus-6A on glia and neurons as potential triggers for central nervous system autoimmunity. J Clin Virol 2006;37 Suppl 1:S11-6. DOI PubMed

74. Morandi E, Tarlinton RE, Tanasescu R, Gran B. Human endogenous retroviruses and multiple sclerosis: Causation, association, or after-effect? Mult Scler 2017;23:1050-5. DOI PubMed 
75. Küry P, Nath A, Créange A, et al. Human endogenous retroviruses in neurological diseases. Trends Mol Med 2018;24:379-94. DOI PubMed PMC

76. Grandi N, Cadeddu M, Blomberg J, Tramontano E. Contribution of type W human endogenous retroviruses to the human genome: characterization of HERV-W proviral insertions and processed pseudogenes. Retrovirology 2016;13:67. DOI PubMed PMC

77. Perron H, Geny C, Laurent A, et al. Leptomeningeal cell line from multiple sclerosis with reverse transcriptase activity and viral particles. Res Virol 1989;140:551-61. DOI PubMed

78. Wang X, Huang J, Zhu F. Human endogenous retroviral envelope protein syncytin-1 and inflammatory abnormalities in neuropsychological diseases. Front Psychiatry 2018;9:422. DOI PubMed PMC

79. Perron H, Germi R, Bernard C, et al. Human endogenous retrovirus type W envelope expression in blood and brain cells provides new insights into multiple sclerosis disease. Mult Scler 2012;18:1721-36. DOI PubMed PMC

80. Perron H, Lazarini F, Ruprecht K, et al. Human endogenous retrovirus (HERV)-W ENV and GAG proteins: physiological expression in human brain and pathophysiological modulation in multiple sclerosis lesions. J Neurovirol 2005;11:23-33. DOI PubMed

81. Morandi E, Tanasescu R, Tarlinton RE, et al. The association between human endogenous retroviruses and multiple sclerosis: a systematic review and meta-analysis. PLoS One 2017;12:e0172415. DOI PubMed PMC

82. Tarlinton R, Wang B, Morandi E, et al. Differential expression of HERV-W in peripheral blood in multiple sclerosis and healthy patients in two different ethnic groups. Front Pharmacol 2020;10:1645. DOI PubMed PMC

83. Perron H, Dougier-Reynaud HL, Lomparski C, et al. Human endogenous retrovirus protein activates innate immunity and promotes experimental allergic encephalomyelitis in mice. PLoS One 2013;8:e80128. DOI PubMed PMC

84. Rolland A, Jouvin-Marche E, Viret C, Faure M, Perron H, Marche PN. The envelope protein of a human endogenous retrovirus-W family activates innate immunity through CD14/TLR4 and promotes Th1-like responses. J Immunol 2006;176:7636-44. DOI PubMed

85. Duperray A, Barbe D, Raguenez G, et al. Inflammatory response of endothelial cells to a human endogenous retrovirus associated with multiple sclerosis is mediated by TLR4. Int Immunol 2015;27:545-53. DOI PubMed PMC

86. Kremer D, Schichel T, Förster M, et al. Human endogenous retrovirus type W envelope protein inhibits oligodendroglial precursor cell differentiation. Ann Neurol 2013;74:721-32. DOI PubMed

87. Sotgiu S, Mameli G, Serra C, Zarbo IR, Arru G, Dolei A. Multiple sclerosis-associated retrovirus and progressive disability of multiple sclerosis. Mult Scler 2010;16:1248-51. DOI PubMed

88. Kornmann G, Curtin F. Temelimab, an IgG4 anti-human endogenous retrovirus monoclonal antibody: an early development safety review. Drug Saf 2020;43:1287-96. DOI PubMed

89. Madeira A, Burgelin I, Perron H, Curtin F, Lang AB, Faucard R. MSRV envelope protein is a potent, endogenous and pathogenic agonist of human toll-like receptor 4: relevance of GNbAC1 in multiple sclerosis treatment. J Neuroimmunol 2016;291:29-38. DOI PubMed

90. Diebold M, Derfuss T. The monoclonal antibody GNbAC1: targeting human endogenous retroviruses in multiple sclerosis. Ther Adv Neurol Disord 2019;12:1756286419833574. DOI PubMed PMC

91. Derfuss T, Curtin F, Guebelin C, et al. A phase IIa randomised clinical study of GNbAC1, a humanised monoclonal antibody against the envelope protein of multiple sclerosis-associated endogenous retrovirus in multiple sclerosis patients. Mult Scler 2015;21:885-93. DOI PubMed

92. Kremer D, Küry P, Hartung HP. ECTRIMS/ACTRIMS 2017: closing in on neurorepair in progressive multiple sclerosis. Mult Scler 2018;24:696-700. DOI PubMed

93. Kremer D, Gruchot J, Weyers V, et al. pHERV-W envelope protein fuels microglial cell-dependent damage of myelinated axons in multiple sclerosis. Proc Natl Acad Sci U S A 2019;116:15216-25. DOI PubMed PMC

94. Leibovitch EC, Jacobson S. Evidence linking HHV-6 with multiple sclerosis: an update. Curr Opin Virol 2014;9:127-33. DOI PubMed PMC

95. Balfour HH, Schmeling DO, Grimm-Geris JM. The promise of a prophylactic Epstein-Barr virus vaccine. Pediatr Res 2020;87:34552. DOI PubMed

96. Cohen JI. Vaccine development for Epstein-Barr virus. Adv Exp Med Biol 2018;1045:477-93. DOI PubMed PMC

97. Rühl J, Citterio C, Engelmann C, et al. Heterologous prime-boost vaccination protects against EBV antigen-expressing lymphomas. $J$ Clin Invest 2019;129:2071-87. DOI PubMed PMC

98. $\quad \mathrm{Bu} \mathrm{W}$, Joyce MG, Nguyen $\mathrm{H}$, et al. Immunization with components of the viral fusion apparatus elicits antibodies that neutralize Epstein-Barr virus in B cells and epithelial cells. Immunity 2019;50:1305-16. :e6. DOI PubMed PMC

99. Messick TE, Smith GR, Soldan SS, et al. Structure-based design of small-molecule inhibitors of EBNA1 DNA binding blocks Epstein-Barr virus latent infection and tumor growth. Sci Transl Med 2019;11:eaau5612. DOI PubMed PMC

100. Oh HS, Neuhausser WM, Eggan P, et al. Herpesviral lytic gene functions render the viral genome susceptible to novel editing by CRISPR/Cas9. Elife 2019;8:e51662. DOI PubMed PMC

101. Maruszak H, Brew BJ, Giovannoni G, Gold J. Could antiretroviral drugs be effective in multiple sclerosis? Eur J Neurol 2011;18:e110-1. DOI PubMed

102. Chalkley J, Berger JR. Multiple sclerosis remission following antiretroviral therapy in an HIV-infected man. J Neurovirol 2014;20:640-3. DOI PubMed

103. Delgado SR, Maldonado J, Rammohan KW. CNS demyelinating disorder with mixed features of neuromyelitis optica and multiple sclerosis in HIV-1 infection. Case report and literature review. J Neurovirol 2014;20:531-7. DOI PubMed

104. Skarlis C, Gontika M, Katsavos S, Velonakis G, Toulas P, Anagnostouli M. Multiple sclerosis and subsequent human 
immunodeficiency virus infection: a case with the rare comorbidity, focus on novel treatment issues and review of the literature. In Vivo 2017;31:1041-6. DOI PubMed PMC

105. Gold J, Marta M, Meier UC, et al. A phase II baseline versus treatment study to determine the efficacy of raltegravir (Isentress) in preventing progression of relapsing remitting multiple sclerosis as determined by gadolinium-enhanced MRI: the INSPIRE study. Mult Scler Relat Disord 2018;24:123-8. DOI PubMed

106. Lin JC, Zhang ZX, Chou TC, Sim I, Pagano JS. Synergistic inhibition of Epstein-Barr virus: transformation of B lymphocytes by alpha and gamma interferon and by 3'-azido-3'-deoxythymidine. J Infect Dis 1989;159:248-54. DOI PubMed

107. Drosu NC, Edelman ER, Housman DE. Could antiretrovirals be treating EBV in MS? Mult Scler Relat Disord 2018;22:19-21. DOI PubMed PMC

108. Drosu NC, Edelman ER, Housman DE. Tenofovir prodrugs potently inhibit Epstein-Barr virus lytic DNA replication by targeting the viral DNA polymerase. Proc Natl Acad Sci U S A 2020;117:12368-74. DOI PubMed PMC

109. Morandi E, Tanasescu R, Tarlinton RE, Constantin-Teodosiu D, Gran B. Do antiretroviral drugs protect from multiple sclerosis by inhibiting expression of MS-Associated retrovirus? Front Immunol 2019;9:3092. DOI PubMed PMC

110. Sundström P. Managing Epstein-Barr virus and other risk factors in MS-Future perspectives. Acta Neurol Scand 2017;136 Suppl 201:31-3. DOI PubMed

111. Marrie RA, Wolfson C. Multiple sclerosis and varicella zoster virus infection: a review. Epidemiol Infect 2001;127:315-25. DOI PubMed PMC

112. Abendroth A, Arvin AM. Immune evasion as a pathogenic mechanism of varicella zoster virus. Semin Immunol 2001;13:27-39. DOI PubMed

113. Ordoñez G, Pineda B, Garcia-Navarrete R, Sotelo J. Brief presence of varicella-zoster vral DNA in mononuclear cells during relapses of multiple sclerosis. Arch Neurol 2004;61:529-32. DOI PubMed

114. Sotelo J, Martínez-Palomo A, Ordoñez G, Pineda B. Varicella-zoster virus in cerebrospinal fluid at relapses of multiple sclerosis. Ann Neurol 2008;63:303-11. DOI PubMed

115. Franciotta D, Bestetti A, Sala S, et al. Broad screening for human herpesviridae DNA in multiple sclerosis cerebrospinal fluid and serum. Acta Neurol Belg 2009;109:277-82. PubMed

116. Burgoon MP, Cohrs RJ, Bennett JL, et al. Varicella zoster virus is not a disease-relevant antigen in multiple sclerosis. Ann Neurol 2009;65:474-9. DOI PubMed PMC

117. Kattimani Y, Veerappa AM. Complex interaction between mutant HNRNPA1 and gE of varicella zoster virus in pathogenesis of multiple sclerosis. Autoimmunity 2018;51:147-51. DOI PubMed

118. Sospedra M, Zhao Y, zur Hausen H, et al. Recognition of conserved amino acid motifs of common viruses and its role in autoimmunity. PLoS Pathog 2005;1:e41. DOI PubMed PMC

119. Komijani M, Bouzari M, Etemadifar M, et al. Torque teno mini virus infection and multiple sclerosis. Int J Neurosci 2011;121:43741. DOI PubMed

120. Scotet E, Peyrat MA, Saulquin X, et al. Frequent enrichment for CD8 T cells reactive against common herpes viruses in chronic inflammatory lesions: towards a reassessment of the physiopathological significance of $\mathrm{T}$ cell clonal expansions found in autoimmune inflammatory processes. Eur J Immunol 1999;29:973-85. DOI PubMed

121. Djelilovic-Vranic J, Alajbegovic A. Role of early viral infections in development of multiple sclerosis. Med Arch 2012;66:37-40. DOI PubMed

122. Sundqvist E, Bergström T, Daialhosein H, et al. Cytomegalovirus seropositivity is negatively associated with multiple sclerosis. Mult Scler 2014;20:165-73. DOI PubMed

123. Zivadinov R, Nasuelli D, Tommasi MA, et al. Positivity of cytomegalovirus antibodies predicts a better clinical and radiological outcome in multiple sclerosis patients. Neurol Res 2006;28:262-9. DOI PubMed

124. Vanheusden M, Stinissen P, 't Hart BA, Hellings N. Cytomegalovirus: a culprit or protector in multiple sclerosis? Trends Mol Med 2015;21:16-23. DOI PubMed

125. Cendrowski W, Polna I, Nowicka K. Measles virus infection and multiple sclerosis: serological studies. J Neurol 1976;213:369-76. DOI PubMed

126. Bernard CC, Townsend E, Randell VB, Williamson HG. Do antibodies to myelin basic protein isolated from multiple sclerosis crossreact with measles and other common virus antigens? Clin Exp Immunol 1983;52:98-106. PubMed PMC

127. Nath A, Wolinsky JS. Antibody response to rubella virus structural proteins in multiple sclerosis. Ann Neurol 1990;27:533-6. DOI PubMed

128. Atkins GJ, Mooney DA, Fahy DA, Ng SH, Sheahan BJ. Multiplication of rubella and measles viruses in primary rat neural cell cultures: relevance to a postulated triggering mechanism for multiple sclerosis. Neuropathol Appl Neurobiol 1991;17:299-308. DOI PubMed PMC

129. Bleau C, Filliol A, Samson M, Lamontagne L. Brain invasion by mouse hepatitis virus depends on impairment of tight junctions and Beta interferon production in brain microvascular endothelial cells. J Virol 2015;89:9896-908. DOI PubMed PMC

130. Martin JR. Herpes simplex virus types 1 and 2 and multiple sclerosis. Lancet 1981;2:777-81. DOI PubMed

131. Bergström T, Alestig K, Svennerholm B, Horal P, Sköldenberg B, Vahlne A. Neurovirulence of herpes simplex virus types 1 and 2 isolates in diseases of the central nervous system. Eur J Clin Microbiol Infect Dis 1990;9:751-7. DOI PubMed PMC

132. Nicoll JA, Kinrade E, Love S. PCR-mediated search for herpes simplex virus DNA in sections of brain from patients with multiple sclerosis and other neurological disorders. J Neurol Sci 1992;113:144-51. DOI PubMed 